Proc. of the International Conference on Mechanochemistry and Mechanical Alloying, Kraków, Poland, June 22-26, 2014

\title{
Core-Shell Mechanocomposites of Drugs with Inorganic Oxides and Hydroxides
}

\author{
T.P. Shakhtshneider ${ }^{a, b, *}$, S.A. Myz ${ }^{a, b}$, E.V. Boldyreva ${ }^{a, b}$, A.I. Nizovski ${ }^{c, d}$ And Rakesh \\ $\mathrm{KUMAR}^{e}$ \\ ${ }^{a}$ Institute of Solid State Chemistry and Mechanochemistry, SB RAS, \\ Kutateladze Str., 18, Novosibirsk, 630128, Russia \\ ${ }^{b}$ Novosibirsk State University, Pirogova Str., 2, Novosibirsk, 630090, Russia \\ ${ }^{c}$ Boreskov Institute of Catalysis, SB RAS, Pr. Lavrentieva, 5, Novosibirsk, 630090, Russia \\ ${ }^{d}$ Omsk State Technical University, Pr. Mira, 11, Omsk, 644050, Russia \\ ${ }^{e}$ National Metallurgical Laboratory, Jamshedpur, 831 007, India
}

\begin{abstract}
The composites of piroxicam and meloxicam with gamma-alumina, aluminium hydroxides (gibbsite and boehmite), alpha and gamma polymorphs of iron(III) oxide having different surface area and morphology were prepared by planetary ball-milling. It has been shown that the initial state of the excipient (specific surface area, particle size and morphology) had a pronounced effect on the formation of the core-shell composites with the drugs and their properties. The X-ray diffraction patterns and IR spectra measured for co-milled samples as well as $\mathrm{X}$-ray photoelectron spectroscopy studies gave evidence that the components of the mixtures interacted with each other and became amorphous, as composites were formed. The drug release from the composites was different as compared with pure drugs, meloxicam and piroxicam behaving differently that can be explained by formation of strong or weak bonds with the active sites of the carriers. In the case of mechanocomposites, the drugs dissolved quickly due to high surface of organic phase in the core-shell composites. The high-porous carriers can serve as the sorbents for the drugs in solution.
\end{abstract}

DOI: 10.12693/APhysPolA.126.1019

PACS: $62.25 .-\mathrm{g}$

\section{Introduction}

In the last years the research in synthesis and structural characterization of organic-inorganic core-shell hybrid materials has received great attention since they have potential for use in many areas of technologies and in pharmacy $[1,2]$. The co-milling can be regarded as an attractive eco-friendly route to prepare the organicinorganic composites [3]. Earlier, we reported [4] the preparation of organic-inorganic hybrid composites of piroxicam and indomethacin with fine porous inorganic oxides, alumina, silica, and magnesia, by high energy ball-milling. The interaction of the components in the composites of piroxicam and meloxicam with highly dispersed alumina was also studied [5]. However, until now, there were no systematic comparative studies of the formation of hybrid mechanocomposites and of their properties, if different forms of the same inorganic excipient were used, which would have the same chemical composition, but different surface or/and particle size and morphology. This paper reports a case study of comparing the formation of mechanocomposites of two drugs (piroxicam and meloxicam) with the two forms of Al-oxyhydroxides (gibbsite and boehmite) or two poly-

*corresponding author; e-mail: shah@solid.nsc.ru morphs of iron(III) oxide $\left(\alpha-\mathrm{Fe}_{2} \mathrm{O}_{3}\right.$ and $\left.\gamma-\mathrm{Fe}_{2} \mathrm{O}_{3}\right)$ that have different surface area and morphology. Aluminum oxohydroxide phases have been suggested as excipients in recent publications [6]. They are more soft than alumina and can serve as the carriers for preparation of mechanocomposites of the drugs. Iron oxides are often used for preparation of magnetic drug delivery systems [7]. Alumina $\left(\gamma-\mathrm{Al}_{2} \mathrm{O}_{3}\right)$ having the less surface area in comparison with the previously studied one $[4,5]$ also was used as excipient.<smiles>Cc1cnc(NC(=O)C2=C(O)c3ccccc3S(=O)(=O)N2C)s1</smiles>

Fig. 1. Molecular structures of (a) piroxicam, (b) meloxicam.

Piroxicam $\left(\mathrm{C}_{15} \mathrm{H}_{13} \mathrm{~N}_{3} \mathrm{O}_{4} \mathrm{~S}\right)$ and meloxicam $\left(\mathrm{C}_{14} \mathrm{H}_{13} \mathrm{~N}_{3} \mathrm{O}_{4} \mathrm{~S}_{2}\right)$ (Fig. 1) are non-steroidal antiinflammatory drugs that are poorly soluble in water. Belonging to "oxicam" family, they are structurallyrelated compounds [8]. Therefore, it was interesting to study the influence of the excipient morphology on the formation of mechanocomposites of these drugs and their dissolution behaviour. 


\section{Materials and methods}

Piroxicam (N-(2-pyridyl)-2-methyl-4-hydroxy-2H-1,2benzothiazine-3-carboxamide 1,1-dioxide) was synthesized at Irkutsk Institute of Chemistry (Irkutsk, Russia) using their technology [9]. Meloxicam (4-hydroxy2-methyl-N-(5-methyl-2-thyazolyl)-2H-benzothiazine3-carboxamide-1,1-dioxide) was purchased from JSC Altaivitaminy (Biisk, Russia).

Gibbsite $\left(\mathrm{Al}_{2} \mathrm{O}_{3} \cdot 3 \mathrm{H}_{2} \mathrm{O}\right)$ was received from the refinery of National Aluminium Company (Bhubaneswar, India). Boehmite $\left(\gamma\right.$-AlOOH or $\left.\mathrm{Al}_{2} \mathrm{O}_{3} \cdot \mathrm{H}_{2} \mathrm{O}\right)$ was prepared from the gibbsite by heating at $350^{\circ} \mathrm{C}$ for $2.5 \mathrm{~h}$. Heating was carried out at $600^{\circ} \mathrm{C}$ for $1 \mathrm{~h}$ to prepare $\gamma-\mathrm{Al}_{2} \mathrm{O}_{3}$. Structural purity of the samples was verified by powder $\mathrm{X}$-ray diffraction. $\gamma-\mathrm{Fe}_{2} \mathrm{O}_{3}$ was purchased from Donetsk Plant of Chemical Reagents (Russia). $\alpha-\mathrm{Fe}_{2} \mathrm{O}_{3}$ was prepared by oxidative thermolysis of iron oxalate dihydrate [10].

The morphology of the samples was examined under Hitachi S-3400N scanning electron microscope and JEM2000-FX (JEOL, Japan) transmission electron microscope with cooling samples by liquid nitrogen. The BET surface area and average pore diameter of the samples were determined by $\mathrm{N}_{2}$-adsorption method using ASAP2020 Micromeritics (USA) equipment.

Milling was carried out under air using AGO-2 (ISSC, Russia) (stainless steel vials $40 \mathrm{ml}$, steel balls of $6 \mathrm{~mm}$ diameter, sample to ball ratio 1:30 (w/w), milling duration varied from 5 to $30 \mathrm{~min}$ ) and Pulverisette 6 (Fritsch, Germany) (stainless steel vials $250 \mathrm{ml}$, steel balls of $10 \mathrm{~mm}$ diameter, sample to ball ratio 1:30 $(\mathrm{w} / \mathrm{w})$, rotation speed $500 \mathrm{~min}^{-1}$, milling duration $\left.30 \mathrm{~min}\right)$ planetary ball mills. The drug to carrier ratio was 1:3 or 1:10 (w/w).

X-ray powder diffraction patterns were recorded using Bruker's D8 Discover diffractometer; $\mathrm{Cu} K_{\alpha}$ radiation and a scanning speed of $2^{\circ} / \mathrm{min}$ were employed. Attenuated total reflectance (ATR) infrared spectroscopy was performed with Digilab Excalibur 3100 FTIR spectrometer (Varian), spectral resolution was better than $\pm 2 \mathrm{~cm}^{-1}$. The X-ray photoelectron spectroscopy (XPS) analysis was performed using a SPECS photoelectron spectrometer (Germany) with $\mathrm{Mg} K_{\alpha}$ X-ray source $(1253.6 \mathrm{eV})$ as described in an earlier paper [5].

To measure the dissolution, solubility tester Varian 705 DS was used. A weighed portion of the sieved sample (particle size of $125-315 \mu \mathrm{m}$ ) comprising the drugexcipient mixture (with or without milling) or drug alone was put into a glass vessel containing $200-250 \mathrm{ml}$ of distilled water at $37 \pm 0.5^{\circ} \mathrm{C}$. The concentration of the drug in solution was measured with a Cary 50 spectrophotometer. Each experiment was repeated three times and the three curves were averaged.

\section{Results and discussion}

\subsection{Composites of the drugs with alumina and} Al-oxyhydroxides

Typical morphological features of the gibbsite, boehmite and $\gamma-\mathrm{Al}_{2} \mathrm{O}_{3}$ are shown in the SEM micrographs given in Fig. 2. Boehmite and $\gamma-\mathrm{Al}_{2} \mathrm{O}_{3}$ retained the typical morphology of the parent phase showing cracks resulting from the escape of water during the thermal transformation of gibbsite. The surface areas of boehmite and $\gamma-\mathrm{Al}_{2} \mathrm{O}_{3}$ were much larger, as compared to gibbsite (Table I). As a result of ball-milling the surface of boehmite decreased $\left(50.1 \mathrm{~m}^{2} / \mathrm{g}\right)$, and that of gibbsite increased $\left(43.2 \mathrm{~m}^{2} / \mathrm{g}\right)$, thus the activated carriers had approximately the same surface area.

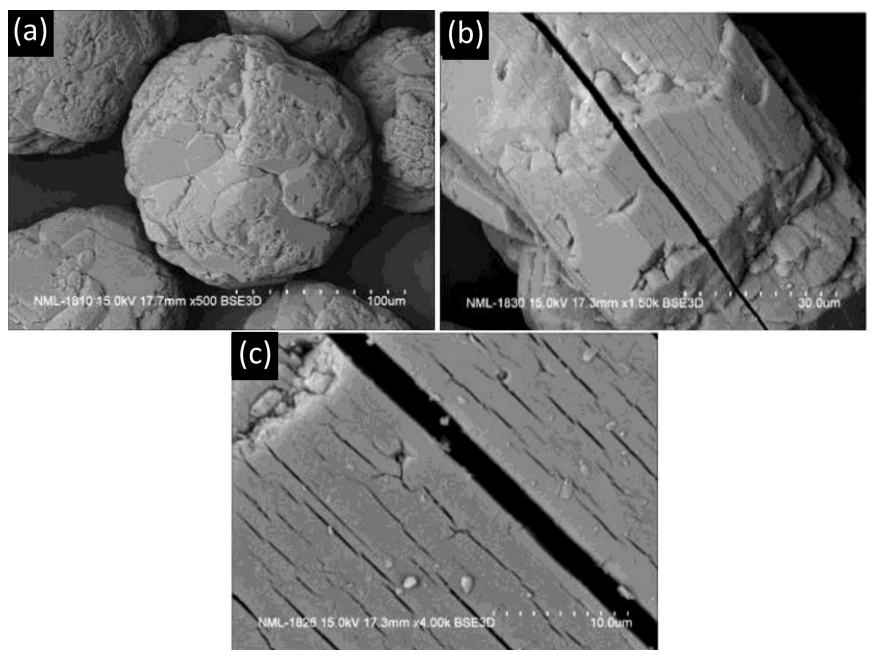

Fig. 2. SEM images of the starting samples: (a) gibbsite, (b) boehmite, (c) $\gamma-\mathrm{Al}_{2} \mathrm{O}_{3}$.

TABLE I

BET surface area and average pore diameters of initial gibbsite, boehmite and $\gamma-\mathrm{Al}_{2} \mathrm{O}_{3}$.

\begin{tabular}{l|c|c|c|c|c}
\hline \hline & $\gamma-\mathrm{Al}_{2} \mathrm{O}_{3}$ & Boehmite & Gibbsite & $\gamma-\mathrm{Fe}_{2} \mathrm{O}_{3}$ & $\alpha-\mathrm{Fe}_{2} \mathrm{O}_{3}$ \\
\hline $\begin{array}{l}\mathrm{BET} \\
\text { surface } \\
\text { area }\left[\mathrm{m}^{2} / \mathrm{g}\right]\end{array}$ & 147.6 & 263.1 & 1.4 & 9.5 & 280.0 \\
\hline $\begin{array}{l}\text { average } \\
\text { pore dia- } \\
\text { meter [nm] }\end{array}$ & 5.65 & 3.23 & 4.97 & 4.3 & n.d. \\
$\begin{array}{l}\text { volume of } \\
\text { the pores } \\
{\left[\mathrm{cm}^{3} / \mathrm{g}\right]}\end{array}$ & n.d. & n.d. & n.d. & 0.02 & 0.19 \\
\hline
\end{tabular}

n.d. - not determined

After ball-milling, the drug phase was completely Xray amorphous in all the samples. In the case of gibbsite and boehmite, the extent of amorphisation of the excipient in the mixtures with the drugs was lower than for excipient alone due to the covering of the surface of the excipient by a layer of the drug.

The changes in the IR spectra for ball-milled mixtures of piroxicam (Fig. 3a) were rather similar for all the excipients and suggested the interaction between the components involving $\mathrm{C}=\mathrm{O}, \mathrm{N}-\mathrm{H}$ groups of piroxicam and the active surface sites of excipients. Terminal and bridged $\mathrm{OH}^{-}$groups as well as Lewis acid and basic 


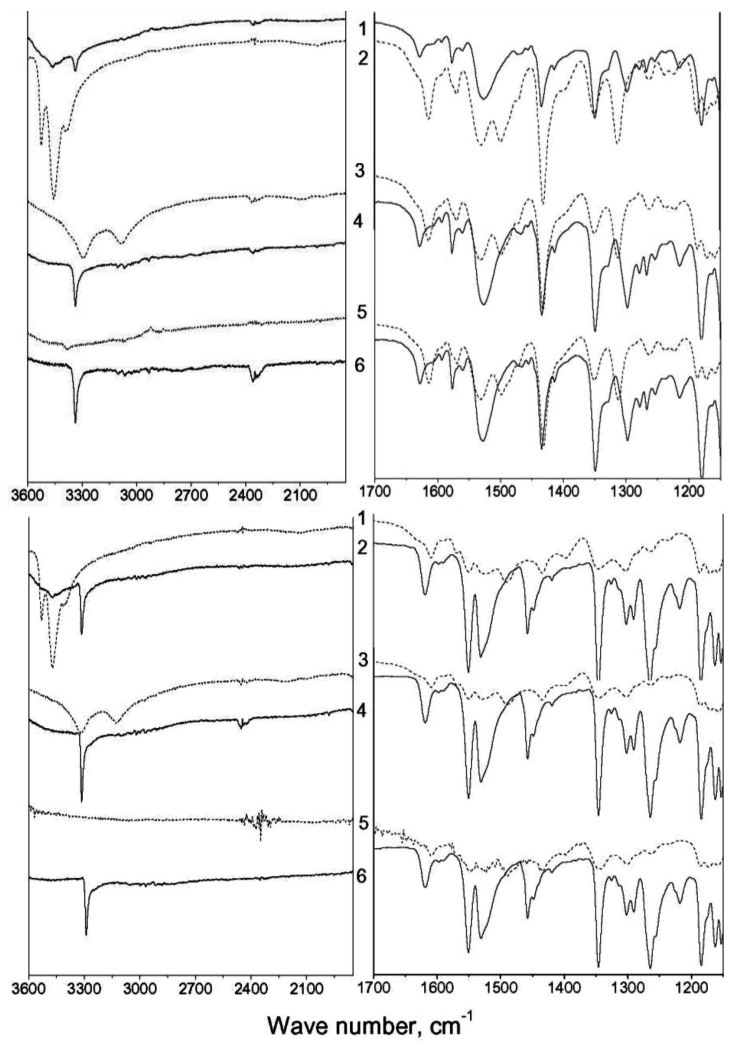

Fig. 3. ATR spectra of the piroxicam (top) and meloxicam (bottom) - excipient physical mixtures (solid lines) and co-milled mixtures (dash lines): 1, 2- with gibbsite, 3, 4 - with boehmite, 5, 6 - with $\gamma-\mathrm{Al}_{2} \mathrm{O}_{3}$.

sites at the surface of alumina [11], can form hydrogen or donor-acceptor bonds with the functional groups of piroxicam molecules. The similarity of the changes in the IR spectra for the ball-milled mixtures and piroxicam metal complexes $[12,13]$ suggested the existence of chelating bonding of piroxicam via the pyridyl nitrogen and the amide oxygen to a Lewis acid site (an aluminium ion with unsaturated coordination), similar to what was observed earlier for piroxicam-alumina composite [5]. The XPS data (Fig. 4a) confirmed that $\mathrm{SO}_{2}$ group was also involved in the interaction with the excipients.

In the IR spectra of meloxicam milled mixtures (Fig. 3b), the changes in $\mathrm{N}-\mathrm{H}$ and $\mathrm{C}=\mathrm{O}$ stretching vibration bands [14] suggested the interaction of meloxicam with the surface of the excipients through the $\mathrm{N}-\mathrm{H}$ and $\mathrm{C}=\mathrm{O}$ groups. The changes in amide II band region, $\mathrm{C}=\mathrm{N}$ stretching vibration and the amide III band involving $\nu(\mathrm{C}-\mathrm{N})$ and $\delta(\mathrm{NH})$ combination confirmed that $\mathrm{N}-\mathrm{H}$ and $\mathrm{C}=\mathrm{O}$ groups of meloxicam were involved in the interaction with the excipients. The $\mathrm{SO}_{2}$ vibrations remained almost unchanged with respect to pure meloxicam, in contrast to the metal meloxicam complexes [14]. In the XPS spectra of meloxicam (Fig. 4b), the appearance of a new energetic state of sulfur of sulfonamide group in the milled mixtures suggested that sulfur atom of sulfon-

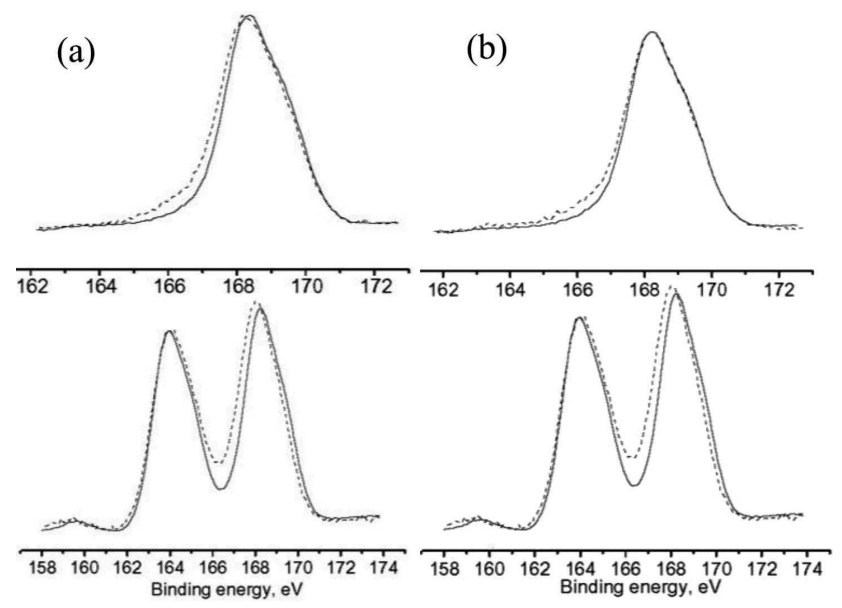

Fig. 4. $S 2 p_{3 / 2,1 / 2}$ XPS core line spectra for piroxicam (top) and meloxicam (bottom) unmilled (solid lines) and milled mixtures (dash lines): (a)with gibbsite, (b) with boehmite.
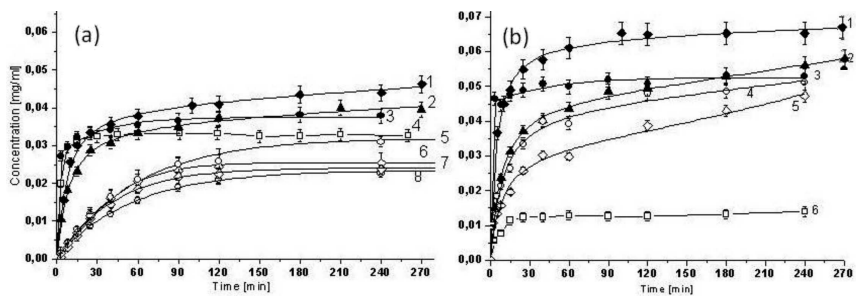

Fig. 5. Dissolution curves (a) of piroxicam: (1) milled with boehmite, (2) milled with $\gamma-\mathrm{Al}_{2} \mathrm{O}_{3},(3)$ milled with gibbsite, (4) initial piroxicam, (5) unmilled piroxicam mixed with unmilled gibbsite, (6) unmilled piroxicam mixed with unmilled boehmite, (7) milled piroxicam mixed with milled boehmite, (8) milled piroxicam mixed with milled gibbsite, (b) of meloxicam: (1) milled with boehmite, (2) milled with $\gamma-\mathrm{Al}_{2} \mathrm{O}_{3}$, (3) milled with gibbsite, (4) milled meloxicam mixed with milled gibbsite, (5) milled meloxicam mixed with milled boehmite, (6) initial meloxicam.

amide group was involved into the interaction with the active sites at the surface of hydroxides.

The dissolution rates of piroxicam from the physical mixtures with the excipients were lower than those for the ball-milled mixtures as well as for pure piroxicam (Fig. 5a). This is despite the fact that the $\mathrm{pH}$ increased in the presence of hydroxides and this could be expected to increase the solubility of piroxicam [15]. It can be assumed that the hydroxides may be used to adsorb the drug from solution. Not only the specific surface area, but also the concentration and strength of the active sites on the excipient surface apparently are important for the dissolution process.

No rapid increase of concentration was observed for the composite samples, possibly due to the drug-excipient interaction. The concentration of piroxicam in solution slightly exceeded the equilibrium value for pure piroxi- 
cam. The maximum increase was observed for the composite of piroxicam with boehmite. This agrees with the fact that boehmite initially had the largest specific surface.

In the case of the composite with alumina, the piroxicam release was slower, probably due to a stronger interaction with the excipient. Nevertheless, the concentration of piroxicam in solution was higher than it was observed for highly dispersed $\gamma-\mathrm{Al}_{2} \mathrm{O}_{3}$ used as an excipient in the earlier study [5]. This may be accounted for different strength and number of active surface sites in the oxides prepared by different ways.

Figure 5b shows the dissolution of meloxicam from the samples obtained. The rate of drug release from the ball-milled mixtures was the highest, probably because of the formation of core-shell composites characterized by increased surface of the drugs. The solubility of the drugs in the case of composite samples was higher than that of the mixtures of the components milled separately and then mixed as well as the solubility of unmilled pure meloxicam.

It is evident from Fig. 5 that the two drugs release is different. The different solubility of piroxicam and meloxicam co-milled composites may be interpreted in terms of the strength of bonds formed between the drugs and the excipients. Taking into account that surface alumina ions with non-saturated coordination act as strong Lewis acid sites at the surface of the carriers [11], the coordinating ability of the drugs may be compared [12$14,16,17]$. It is possible that piroxicam and meloxicam can undergo complexation with the surface active sites of the carriers leading to formation of bonds of different strength, and, consequently, different release of the drugs on dissolution.

\subsection{Composites of the drugs with the polymorphs of iron oxide}

It is evident from the TEM micrographs that under milling, the $\gamma-\mathrm{Fe}_{2} \mathrm{O}_{3}$ particles were covered by a thin layer of the drug (Fig. 6). In the co-milled mixtures of the drugs with $\gamma-\mathrm{Fe}_{2} \mathrm{O}_{3}$, the intensity of X-ray diffraction peaks of the drugs significantly decreased.

There were no changes in the IR spectra of $1: 3$ piroxicam-milled mixture in comparison with the physical mixture of the components (Fig. 7). In the IR spectra of $1: 10$ piroxicam $-\gamma-\mathrm{Fe}_{2} \mathrm{O}_{3}$ milled mixture, the $1631 \mathrm{~cm}^{-1}$ band attributed to $\mathrm{C}=\mathrm{O}$ stretching vibrations of piroxicam significantly shifted. The changes in the regions of $\mathrm{OH}$ and $\mathrm{C}=\mathrm{N}$ stretching vibrations as well as amide II and amide III bands were also observed, some of them are marked at the Fig 7 . These changes can be attributed to formation of bonds between $\mathrm{C}=\mathrm{O}$ group and pyridyl nitrogen of piroxicam with the active centers at the surface of the oxide such as coordinatively unsaturated $\mathrm{Fe}^{3+}$ ions [18]. The hydrogen bonding between piroxicam $\mathrm{OH}$-groups and $\mathrm{OH}^{-}$groups at the surface of $\gamma-\mathrm{Fe}_{2} \mathrm{O}_{3}$ is also possible. Due to formation of complexes of piroxicam with the surface centres of iron oxide par-

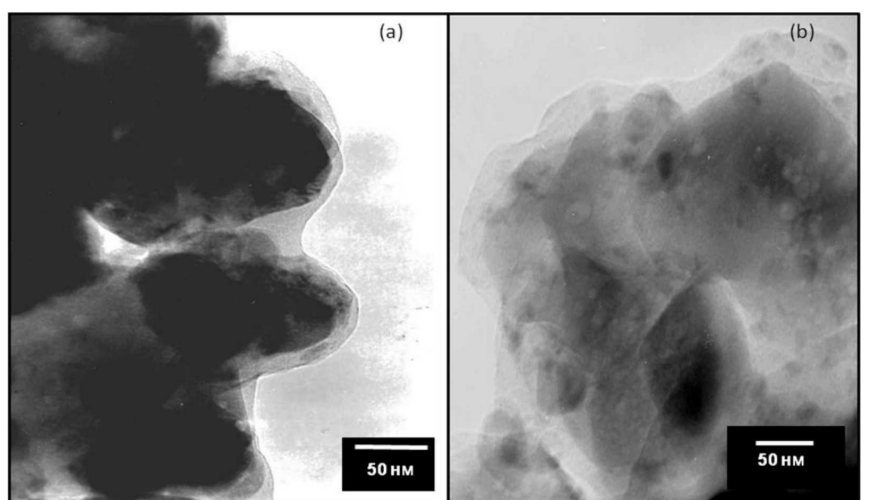

Fig. 6. TEM images of the ball-milled mixtures of $\gamma$ $\mathrm{Fe}_{2} \mathrm{O}_{3}$ with (a) piroxicam and (b) meloxicam.

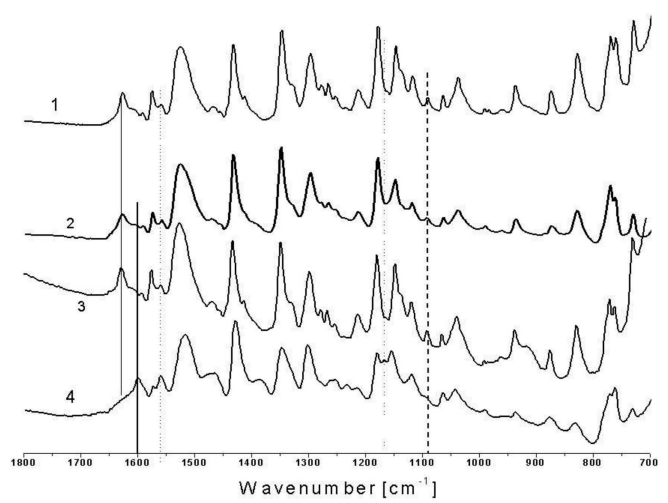

Fig. 7. ATR spectra of (1) 1:3 piroxicam $-\gamma-\mathrm{Fe}_{2} \mathrm{O}_{3}$ physical mixture, (2) the same mixture milled in AGO2 mill for 15 min, (3) 1:10 piroxicam- $\gamma-\mathrm{Fe}_{2} \mathrm{O}_{3}$ physical mixture, (4) the same mixture milled in AGO-2 mill for 15 .

ticles, the drug release was slower than for initial piroxicam (Fig. 8).

The same results were obtained for meloxicam (Fig. 8). Thus, $\gamma-\mathrm{Fe}_{2} \mathrm{O}_{3}$ is a perspective material for design of magnetic carriers for targeting drug delivery [19].

It was interesting to study the influence of morphology of the oxide on the formation of composites and their properties. With this purpose, the $\alpha-\mathrm{Fe}_{2} \mathrm{O}_{3}$ prepared by thermal decomposition of iron oxalate dihydrate was used as a carrier. $\alpha-\mathrm{Fe}_{2} \mathrm{O}_{3}$ was a pseudomorphous high-porous product consisting from the ordered nanocrystals [10] After ball-milling with $\alpha-\mathrm{Fe}_{2} \mathrm{O}_{3}$, amorphization of the meloxicam was observed. In the IR spectra of the milled 1:3 and 1:10 meloxicam- $\alpha-\mathrm{Fe}_{2} \mathrm{O}_{3}$ mixtures in comparison with the physical mixtures of the components, the bands attributed to stretching vibrations of $\mathrm{N}-\mathrm{H}\left(3291 \mathrm{~cm}^{-1}\right)$, $\mathrm{C}=\mathrm{O}\left(1621 \mathrm{~cm}^{-1}\right), \mathrm{SO}_{2}\left(1162 \mathrm{~cm}^{-1}\right)$ groups as well as amide II $(\nu(\mathrm{C}-\mathrm{N})+\delta(\mathrm{NH}))\left(1551 \mathrm{~cm}^{-1}\right)$ band broadened and shifted suggesting the interaction of the components.

The dissolution experiments revealed that the oxide was a very good sorbent and, in the case of the physical 


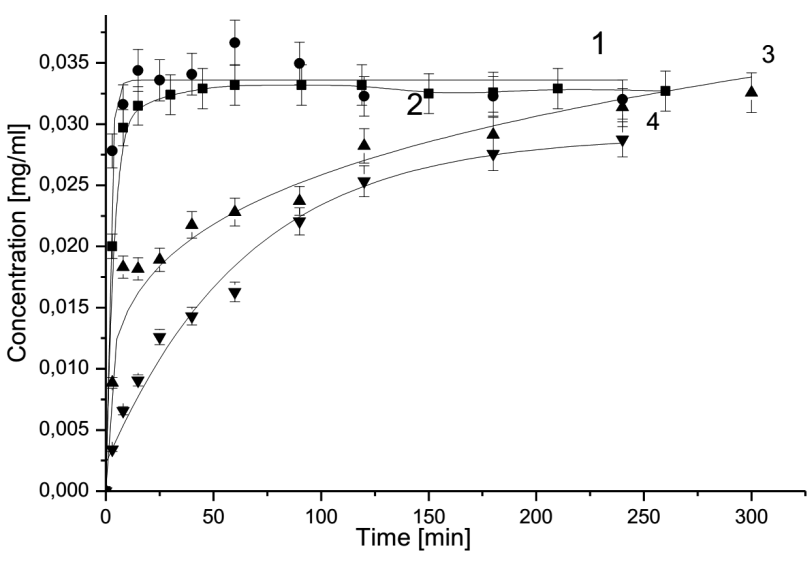

Fig. 8. Dissolution curves of (1) initial meloxicam, (2) initial piroxicam, (3) 1:10 piroxicam- $\gamma-\mathrm{Fe}_{2} \mathrm{O}_{3}$ mixture milled in AGO-2 mill for $10 \mathrm{~min}$, (4) 1:3 meloxicam- $\gamma$ $\mathrm{Fe}_{2} \mathrm{O}_{3}$ mixture milled in AGO-2 mill for $10 \mathrm{~min}$.

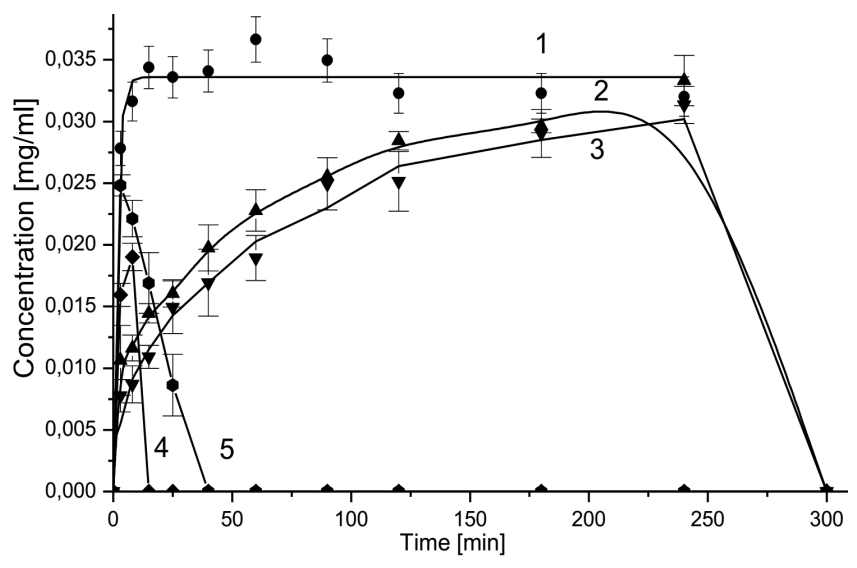

Fig. 9. Dissolution curves of (1) initial meloxicam, (2) $1: 3$ and (3) 1:10 milled meloxicam- $\alpha-\mathrm{Fe}_{2} \mathrm{O}_{3}$ mixtures (AGO-2 mill, $15 \mathrm{~min}$ ), (4) 1:10, and (5) 1:3 unmilled meloxicam $-\alpha-\mathrm{Fe}_{2} \mathrm{O}_{3}$ mixtures.

mixtures of the initial components, the sorption of the drug was observed from the solution (Fig. 9). Nevertheless, in the case of co-milled mixtures, the drug slowly released into water and then its concentration fell down sharply. This fact suggested that during co-milling, the high-porous particles of the oxide were covered by a layer of the drug and only after dissolution of this layer the oxide can act as a sorbent. As a result of co-milling, the decrease of surface area and the volume of the pores was observed (Table II). The size of the pores increased due to their aggregation. It could be suggested that the drug penetrated into the oxide pores during ball-milling. After drug release into water, the pores became free and the oxide acted as a sorbent.

\section{Conclusion}

The composites of piroxicam and meloxicam with different forms of alumina, gibbsite, boehmite as well as
TABLE II

BET surface area and average pore diameters of milled $\alpha-\mathrm{Fe}_{2} \mathrm{O}_{3}$ and 1:3 meloxicam- $\alpha-\mathrm{Fe}_{2} \mathrm{O}_{3}$ mixture.

\begin{tabular}{l|c|c|c}
\hline \hline Sample & $\begin{array}{c}\text { BET surface } \\
\text { area }\left[\mathrm{m}^{2} / \mathrm{g}\right]\end{array}$ & $\begin{array}{c}\text { Average pore } \\
\text { diameter }[\mathrm{nm}]\end{array}$ & $\begin{array}{c}\text { Volume } \\
\text { of pores } \\
{\left[\mathrm{cm}^{3} / \mathrm{g}\right]}\end{array}$ \\
\hline $\begin{array}{l}\text { Milled } \alpha-\mathrm{Fe}_{2} \mathrm{O}_{3} \\
(\mathrm{AGO}-2,15 \mathrm{~min})\end{array}$ & 63.0 & 5.89 & 0.09 \\
\hline $\begin{array}{l}1: 3 \text { meloxicam- } \alpha-\mathrm{Fe}_{2} \mathrm{O}_{3} \\
\text { milled mixture } \\
(\mathrm{AGO}-2,15 \mathrm{~min})\end{array}$ & 4.39 & 46.3 & 0.05 \\
\hline
\end{tabular}

iron(III) oxide polymorphs were prepared using planetary ball milling. Piroxicam and meloxicam interacted chemically with the oxyhydroxide/oxide excipients. Amide, sulfonamide groups, and pyridyl/thiazolyl nitrogen atoms of piroxicam and meloxicam form non-covalent bonds with the active sites at the surface of the excipients. In the case of composites, the solubility of drugs was higher than the solubility of pure drugs. The dispersity and morphology of the excipients used for preparation of mechanocomposites influenced the drug dissolution, even though after ball-milling the surface area of the excipient decreased. When the strong bonds were formed the excipients of high surface area can serve as the sorbents; the concentration of the drug in solution was rather low. In other case, using the carriers of higher surface area increases the solubility of the drug. The drugs with a similar molecular structure, piroxicam and meloxicam, behaved quite differently when co-milled with the same inorganic components selected as excipients. The effect of the excipient on the drug solubility was larger for meloxicam composites than for the piroxicam ones. This can be explained by the differences in the interaction of the two drugs with the surface active sites of excipients leading to formation of bonds of different strength. The observed effects are of great importance for the development of methods of solubilizing poorly water-soluble drugs by preparing mechanocomposites with inorganic carriers.

\section{Acknowledgments}

The financial support received from Department of Science and Technology (India) and Russian Foundation for Basic Research (projects nos. 09-03-92658 IND and 13-03-92704_IND) as well as from Russian Academy of Sciences (the Program "Fundamental Sciences for Medicine") is gratefully acknowledged.

\section{References}

[1] Y. Chujo, KONA Powder Particl. 25, 255 (2007).

[2] A.T. Ten Cate, J. Eversdijk, K.J.C. van Bommel, in: Abstr. First Int. Conf. on Multifunctional, Hybrid and Nanomaterials, Tours (France), 2009, p. A12.

[3] E. Boldyreva, Chem. Soc. Rev. 42, 7719 (2013). 
[4] T.P. Shakhtshneider, S.A. Myz, M.A. Mikhailenko, T.N. Drebushchak, V.A. Drebushchak, A.P. Fedotov, A.S. Medvedeva, V.V. Boldyrev, Mater. Manufact. Proc. 24, 1064 (2009).

[5] T.P. Shakhtshneider, S.A. Myz, M.A. Dyakonova, V.V. Boldyrev, E.V. Boldyreva, A.I. Nizovskii, A.V. Kalinkin, Rakesh Kumar, Acta Phys. Pol. A 120, 272 (2011).

[6] S.C. Shen, P.S. Chow, F.X. Chen, R.B.H. Tan, J. Cryst. Growth 292, 136 (2006).

[7] S.A. Wahajuddin, Int. J. Nanomed. 7, 3445 (2012).

[8] N.E.A. El-Gamel, J. Coord. Chem. 62, 2239 (2009).

[9] A.S. Medvedeva, A.I. Podskrebyshev, L.P. Safronova, M.G. Voronkov, A.S. Zaks, RF Patent No. 2109738, (Chem. Abstr. 133, 252444u (2000)).

[10] D.A. Yatsenko, V.P. Pakharukova, S.V. Tsybulya, A.A. Matvienko, A.A. Sidel'nikov, J. Struct. Chem. 53, 548 (2012).

[11] E.V. Kul'ko, A.S. Ivanova, A.A. Budneva, E.A. Paukshtis, React. Kinet. Catal. Lett. 88, 381 (2006).
[12] E. Santi, M.H. Torre, E. Lremer, S.B. Etcheverry, E.J. Baran, Vibrat. Spectrosc. 5, 285 (1993).

[13] R. Cini, G. Giorgi, A. Cinquatini, C. Rossi, M. Sabat, Inorg. Chem. 29, 5197 (1990).

[14] S. Defazio, R. Cini, Polyhedron 22, 1355 (2003).

[15] P. Luger, K. Daneck, W. Engel, G. Trummlitz, K. Wagner, J. Pharm. Sci. 4, 175 (1996).

[16] P. Christofis, M. Katsarou, A. Papakyriakou, Y. Sanakis, N. Katsaros, G. Psomas, J. Inorg. Biochem. 99, 2197 (2005).

[17] S. Defazio, R. Cini, J. Chem. Soc. Dalton Trans. 9 1888 (2002).

[18] A.A. Davydov, IR Spectroscopy in the Chemistry of Surface of Oxides, Publ. House "Nauka", Novosibirsk 1984.

[19] V.P. Isupov, T.P. Shakhtshneider, S.A. Myz, V.V. Boldyrev: Method of obtaining of magnetic composite on the base of iron oxides and molecular crystals, RF Patent No. 2421243, Publ. No. 17, Publ. Date: 20.06.2011. 